\title{
ON SOME MECHANICAL PROPERTIES AND WEAR BEHAVIOR OF SINTERED BRONZE BASED COMPOSITES REINFORCED WITH SOME ALUMINIDES MICROADDITIVES
}

\author{
E. FELDSHTEIN*, P. KIEŁEK and T. KIEŁEK \\ Institute of Mechanical Engineering and Machine Operation \\ University of Zielona Góra \\ ul. Prof. Z. Szafrana 4 \\ 65-516 Zielona Góra, POLAND \\ E-mail: E.Feldsztein@ibem.uz.zgora.pl \\ L. DYACHKOVA and A. LETSKO \\ Institute of Powder Metallurgy, Belarusian National Academy of Sciences \\ ul. Platonova 41, Minsk, 220005 BELARUS
}

\begin{abstract}
In the paper, the changes in some mechanical properties and wear behavior of $\mathrm{CuSn} 10$ sintered bronze and MMCs based on this bronze reinforced with composite ultrafine aluminide powders $\mathrm{FeAl} / 15 \% \mathrm{Al}_{2} \mathrm{O}_{3}$, $\mathrm{NiAl} / 15 \% \mathrm{Al}_{2} \mathrm{O}_{3}$ and $\mathrm{Ti}-46 \mathrm{Al}-8 \mathrm{Cr}$ are described. It was observed that the presence of aluminides in the MMCs leads to an increase in the hardness, but the flexural strength may increase or decrease depending on the type of aluminide. The presence of aluminides in the MMC reduces the wear rate considerably. It is decreased in the direction of $\mathrm{FeAl} / 15 \% \mathrm{Al}_{2} \mathrm{O}_{3} \rightarrow \mathrm{NiAl} / 15 \% \mathrm{Al}_{2} \mathrm{O}_{3} \rightarrow \mathrm{Ti}-46 \mathrm{Al}-8 \mathrm{Cr}$ aluminides and for the best $\mathrm{MMC}$ composition the advantage is about 20 times. In the MMCs wear process, micro-craters are formed on the contact surface and it is the principal reason of a decrease in the wear rate.
\end{abstract}

Key words: metal-matrix composites (MMCs), mechanical properties, surface analysis, wear.

\section{Introduction}

Powder metallurgy $(\mathrm{P} / \mathrm{M})$ materials are extensively used nowadays because of their low cost and no or a minimum need for metalworking processes. In addition, these materials have unique properties that cannot be obtained by standard melting-casting processes.

Copper-based P/M materials are widely used in industry equally with iron and steel, and aluminumbased P/M materials (Nadkarni [1]). They are used for self-lubricating bearings and as friction materials in brushes, filters, structural parts, electrical parts, etc. P/M bronzes typically originate as premixes consisting of elemental copper and tin powders with some technological additives. It is known that copper and lead, which have limited solubility in each other, are difficult to alloy by conventional ingot metallurgy. P/M bronze parts are frequently selected for structural applications, because of corrosion and wear resistance of bronze. But low hardness and strength, and poor wear resistance limits their usage (Nadkarni [1] and Cusano $[2])$.

The properties of sintered bronzes can be improved with the incorporation of reinforcing particulates by developing bronze based metal matrix composites (MMC). The use of various particulates to reinforce the material has been investigated in numerous publications. Carbides, borides and metal oxides are most widely used for reinforcement due to their high hardness and wear properties, particularly TiC (Akhtar et al. [3]),

\footnotetext{
${ }^{*}$ To whom correspondence should be addressed
} 
WC (Deshpande and Lin [4]), $\mathrm{SiC}$ (Tjong and Lau [5]), $\mathrm{TiB}_{2}$ (Tjong and Lau [6] and $\underline{\mathrm{Tu}}$ et al. [7]), $\mathrm{Al}_{2} \mathrm{O}_{3}$ (Das et al. [8] and Dyachkova and Feldshtein [9]).

On the other hand, reinforcements with different intermetallic particulates have also been investigated. Intermetallics are of interest because of the variety of chemical composition and variety of their physical and mechanical properties. In the research of Díaz et al. [10] hardening of an Al-based material with $\mathrm{Ni}_{3} \mathrm{Al}$ intermetallic particles was studied. It was found that $\mathrm{Ni}_{3} \mathrm{~A} 1$ intermetallic particles act as load-bearing elements due to a strong bonding between these particles and the $\mathrm{Al}$ matrix. The $\mathrm{P} / \mathrm{M}$ method is successful in processing these wear-resistant AMCs for tribological applications. In the investigation of Da Costa et al. [11], the wear behaviour of aluminum MMCs reinforced with different nickel aluminides was investigated. It was concluded that reinforcing aluminum alloys with intermetallics increases highly the wear behaviour by the order of two-three times compared to the base alloy. In the research of Tu et al. [12], the friction and wear behavior of $\mathrm{Cu}-\mathrm{Fe}_{3} \mathrm{Al} \mathrm{P} / \mathrm{M}$ composites in dry sliding is described. It was found that the coefficients of friction for these composites were independent of the contact pressure and the sliding speed variation. With increasing the volume fraction of $\mathrm{Fe}_{3} \mathrm{Al}$ particle, the wear resistance of the composites increased at lower contact pressures, but not at higher contact pressures, and the coefficients of friction decreased slightly. The wear rate of $\mathrm{Cu}-\mathrm{Fe}_{3} \mathrm{Al}$ composites decreased with the sliding speed.

The laminar copper-intermetallic composite structure and properties are examined by Konieczny, [13]. $\mathrm{Cu}_{4} \mathrm{Ti}, \mathrm{Cu}_{2} \mathrm{Ti}$ and $\mathrm{CuTi}$ particles were used to reinforce copper. The results showed that the hardness of the intermetallic layers in the composites is significantly higher than the hardness of the copper layers and the wear resistance of the composites increases with an increase in the thickness of intermetallic layers and is similar to that of CuSn8 bronze. The formation and examination of the structure and properties of sintered copper matrix composites containing aluminum-ferric intermetallic phases is described by Konieczny and Mola [14]. Two kinds of additives were used: AlFe particles and $\mathrm{AlFe}_{3}+\alpha$ (solid solution of aluminium and copper in iron) particles. It was found that composites containing AlFe phase have high electrical conductivity and also high microhardness of intermetallic phases. Intermetallic $\mathrm{AlFe}_{3}+\alpha$ phases have a lower average microhardness in comparison with AlFe. But on the other hand, their advantage is a diffusion joint between particles and the matrix.

The results of the investigation on the properties and wear behaviors of $\left(\mathrm{Ni}_{3} \mathrm{Al}\right) \mathrm{p}$ reinforced $\mathrm{Cu}$ matrix composites were presented by Çelikyürek [15]. The experiments showed that the density and electric conductivity of the composites decrease with increasing particle fraction. The composites have lower compression yield strengths in comparison with unreinforced sintered copper. The coefficient of friction of $\mathrm{Cu}$ increased with increasing the sliding speed whereas the coefficient of friction of composites decreased with an increase in the sliding speed, and values of coefficients of friction for composites are increased in comparison with sintered copper. The wear resistance of investigated composites was improved considerably with an addition of $\mathrm{Ni}_{3} \mathrm{Al}$ and increased with an increase in $\mathrm{Ni}_{3} \mathrm{Al}$ fraction. With the addition of $\mathrm{Ni}_{3} \mathrm{Al}$ to copper, the direct copper-counterface contact was reduced that resulted in an increase of wear resistance. In this paper, some mechanical properties and wear behavior of sintered bronze based composites reinforced with a micrometric quantity of different aluminides are studied.

\section{Materials researched}

Ready-made powders of copper with an average particle size of $25 \mu \mathrm{m}$ and tin with an average particle size of $20 \mu \mathrm{m}$ were used to produce the base sintered bronze CuSn10. It is known that alloying of copper with tin enhances the operational properties by improving the embeddability, conformability and resistance to seizure (Zeren at al. [16]; Zeren [17]; Goudarzi et al. [18]; Gebretsadik et al. [19].

Aluminides particulates were obtained by mechanical activated self-propagating high-temperature synthesis method and their sizes were $3 \mu \mathrm{m}$.

The mixture of components $\mathrm{Cu}+10 \mathrm{wt} \% \mathrm{Sn}$ and $\mathrm{Cu}+10 \mathrm{wt} \% \mathrm{Sn}+(0.2$, or 0.5 , or $1 \mathrm{wt} \%)$ aluminides was prepared in a mixer of "drunken barrel" type for $0.5 \mathrm{~h}$. The samples were pressed with a hydraulic press to a relative density of $85-88 \%$ and sintered in the atmosphere of an endothermic gas at $780-800^{\circ} \mathrm{C}$. 


\section{Research conditions}

The microstructures of cross sections of the specimens were examined using the "MEF-3" optical microscope. Cross sections were etched in a 3\% solution of ferric chloride in ethanol.

To provide the desired roughness the work surfaces of the MMC samples were ground using the TIA $350 \times 127 \times 50-99 \mathrm{~A} 46 \mathrm{M} 5 \mathrm{~V}$ wheel with a depth of $0.015 \mathrm{~mm}$, the grinding speed of $24 \mathrm{~m} / \mathrm{s}$ and longitudinal table feed of $3 \mathrm{~m} / \mathrm{min}$.

Roughness parameters were measured with the TR 200 profilometer. MIRA.

Surface textures were analyzed using Scanning Electron Microscopes JEOL JSM-5600LV and

The hardness was determined by the Brinell hardness tester using the ball of $2.5 \mathrm{~mm}$ in diameter and the load of $1839 \mathrm{~N}$.

The strength of the MMCs was determined in three-point bending using the "Instron-1195" testing machine with the cross head speed of $2 \mathrm{~mm} / \mathrm{min}$.

Tribological tests were performed in conditions of concentrated and distributed contact. Concentrated contact tests were carried out using the A-135 tester of Amsler type at the sliding speed of 0.45 $\mathrm{m} / \mathrm{s}$. Tests were performed with the stable loads of $500 \mathrm{~N}$ and $1000 \mathrm{~N}$ and with an increased load in the range 300-1000 N. An increased load was applied with a step increase of $100 \mathrm{~N}$ every $5 \mathrm{~min}$. The samples were made of MMC, and counter-bodies (rollers) were made of 41Cr4 EN 10083-1:2006 steel in the hardened state, hardness of 45-50 HRC. The test time was 1 hour. The L $-\mathrm{AN} 68$ machine oil with the flow rate of 30 drops per minute was used as the lubricant. The values of the momentary coefficients of friction were calculated from the measured values. The temperature in the friction zone and wear were controlled too. Temperatures were measured with a thermocouple. The magnitude of the segmental wear of samples was registered using an optical microscope with an accuracy of $0.005 \mathrm{~mm}$.

Distributed contact tests were carried out using the MT-2 tester of "pin-on-disc" type. Rotating counter-bodies were made of AISI 1045 steel and had a disc form and hardness of 42-45 HRC. They were in contact with the flat surfaces of the three pin samples $10 \mathrm{~mm}$ in diameter. Tests were carried out at the sliding speed of $7 \mathrm{~m} / \mathrm{s}$ in two stages. In the first stage, average coefficients of friction were determined under the load increasing from $10 \mathrm{~N}$ until seizure occurred. In the other stage, the wear rates were determined under a stable load equal to $50 \mathrm{~N}$ and the test time of $1 \mathrm{~h}$. I-20 industrial oil was used as the lubricant with the flow rate of $8-10$ drops per minute. The magnitude of the linear wear was registered using an optimeter with an accuracy of $0.001 \mathrm{~mm}$.

\section{Results of research}

The typical structures of some of the test materials are shown in Fig.1. The CuSn10 sintered bronze has the structure of $\mathrm{Sn}$ in $\mathrm{Cu}$ solid solution of variable concentration with $\alpha+\delta$ eutectoid inclusions, twin crystals and a certain amount of pores (Fig.1a).

After the introduction of all tested intermetallic compositions a significant refinement of the structure is observed (Figs 1b, c, d) as a result of increasing the recrystallization centers and slowing secondary recrystallization.

In the material with additives of $\mathrm{NiAl} / 15$ wt. $\% \mathrm{Al}_{2} \mathrm{O}_{3}$ intermetalloid, there is a local alloying nickelcopper matrix, and a decrease in porosity and minimal content of $\alpha+\delta$ - eutectoid are observed (Fig.1c) in comparison with the materials with additives of $\mathrm{FeAl} / 15 \% \mathrm{Al}_{2} \mathrm{O}_{3}$ (Fig.1b), and Ti-8Cr-46Al (Fig.1d) intermetalloids.

The hardness of the tested materials depends on their composition (Fig.2a). The CuSn10 sintered bronze hardness was equal to $\sim 60 \mathrm{HB}$ and the hardness of reinforced composites increased about 1.2-1.6 times. The tendency for a slight decrease in hardness was observed in the direction of $\mathrm{NiAl} \rightarrow \mathrm{FeAl} \rightarrow \mathrm{TiCrAl}$ aluminides. 
The residual porosity of tested materials is stable with the exception of MMC with FeAl aluminides (Fig.2b). These additives decrease the residual porosity about 1.6 times. The presence of FeAl aluminides in the metal matrix improves joining of powder particles during sintering that affects the porosity.
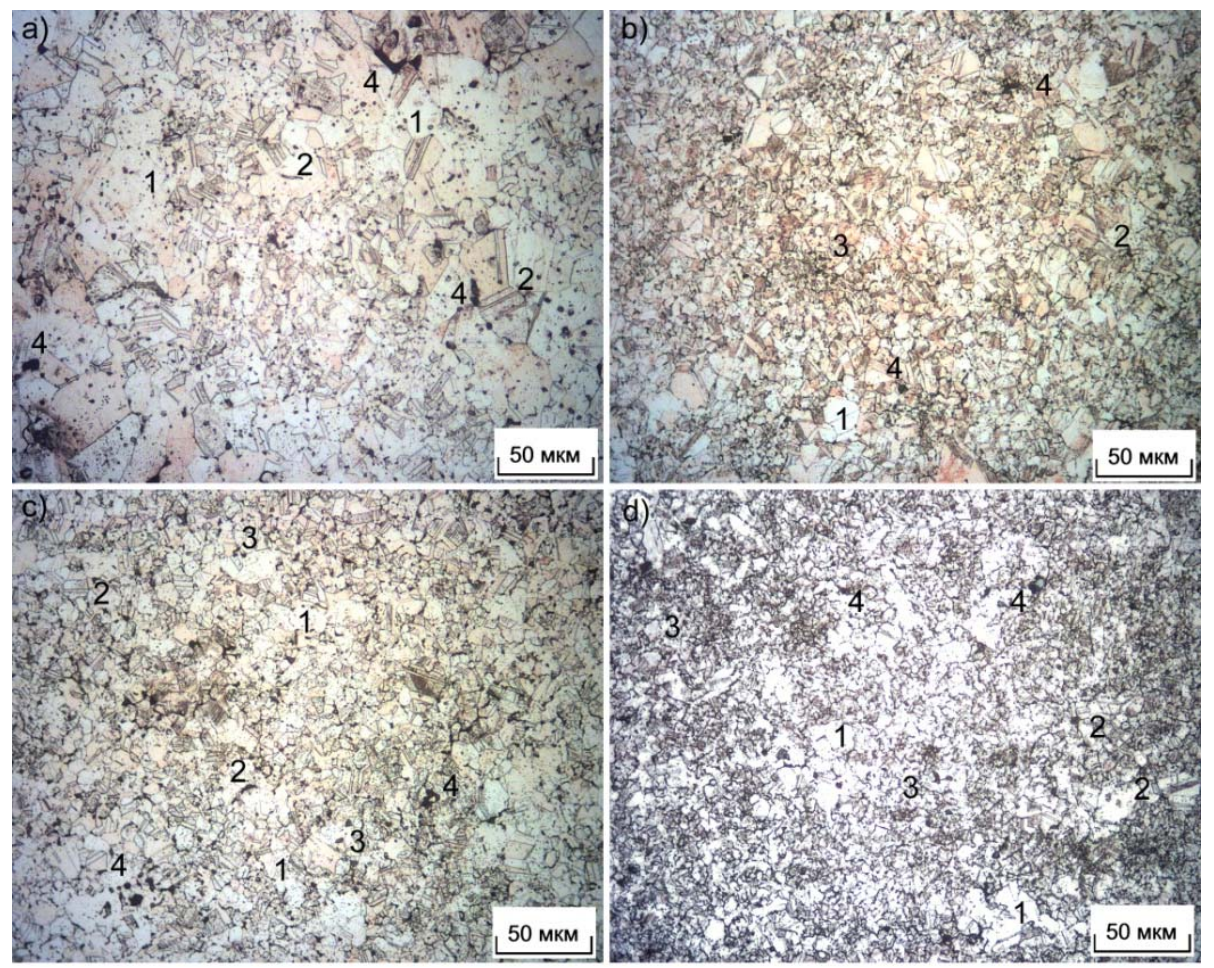

Fig.1. The microstructure of the powder bronze with the additions of aluminides: (a) CuSn10; (b) CuSn10+FeAl; (c) CuSn10+NiAl; (d) CuSn10+TiCrAl; 1 - eutectoid inclusions, 2 - twin crystals, 3 - aluminides, 4 - pores.
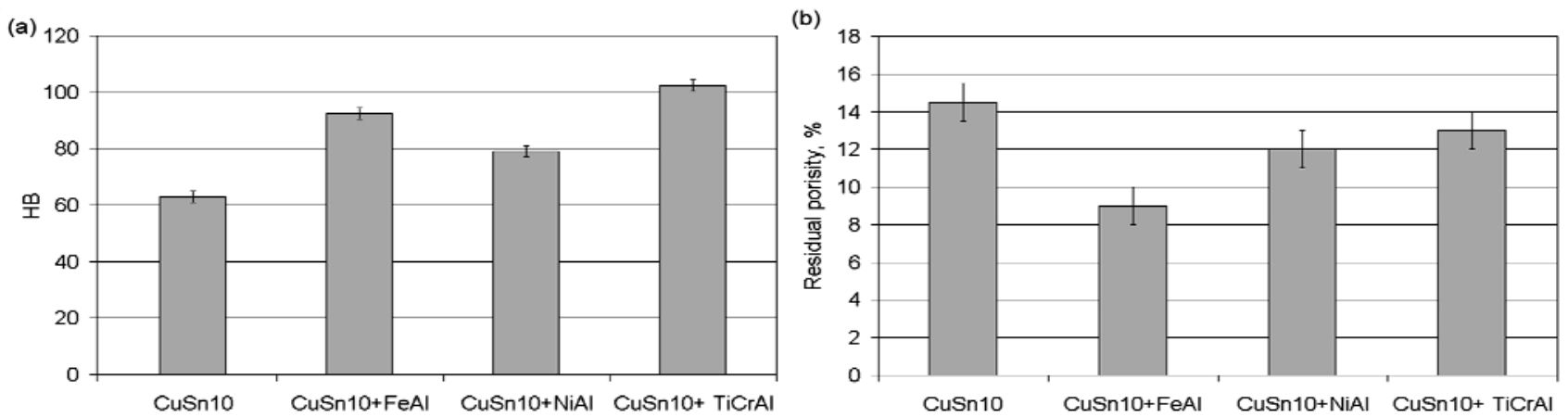

Fig.2. The influence of reinforcing particulates on hardness (a) and residual porosity (b) of tested materials.

In our opinion, the findings can be explained by differences in the state of reinforcing particulates at the grain boundaries. Interactions between the base material and reinforcing particulates are very important, because the properties of the MMCs depend not only on the matrix, particulates and the volume fraction, but also on the distribution of reinforcing particulates and interface bonding between the particulates and the matrix (Sahin [20]), since diffusion layers form at the interface. 
The results of testing the flexural strength of materials based on sintered bronze with reinforced additives are shown in Fig.3. It can be seen that the composition of reinforcing additives affects this property. The best results were achieved for MMCs reinforced with NiAl based compound and the worst for TiCrAl based compound. It is due to the features of the boundary interfaces, as it is in the case of the hardness and porosity.

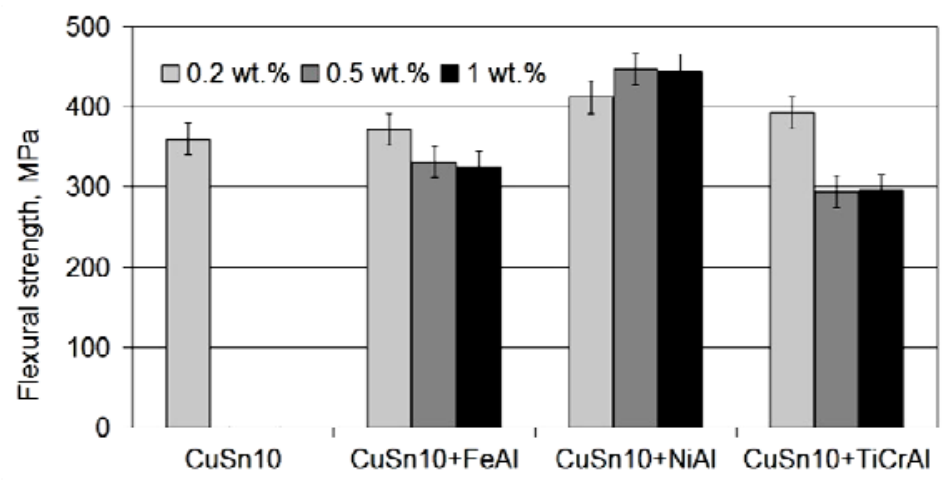

Fig.3. The influence of reinforcing particulates on the flexural strength of tested materials.

Regardless of its composition, increasing the additive content to $1 \%$ leads to a considerable, nearly 1.2-1.4 times, weakening of grain boundaries and a reduction in strength. It is due to the fact that intermetallic particulates are most frequently located there. The heterogeneity of the grain sizes is observed, too.

Changes in the structure and mechanical properties of composite materials affect the characteristics of the texture of friction surfaces. Typical profile records of the friction surfaces of the in-situ and wear samples made of the materials investigated are shown in Fig.4. Values of some roughness parameters (the arithmetic mean deviation of the assessed profile $R a$, maximum height of the assessed profile $R z$ and mean width of the surface element $R S m$ ) are shown in Fig.5.

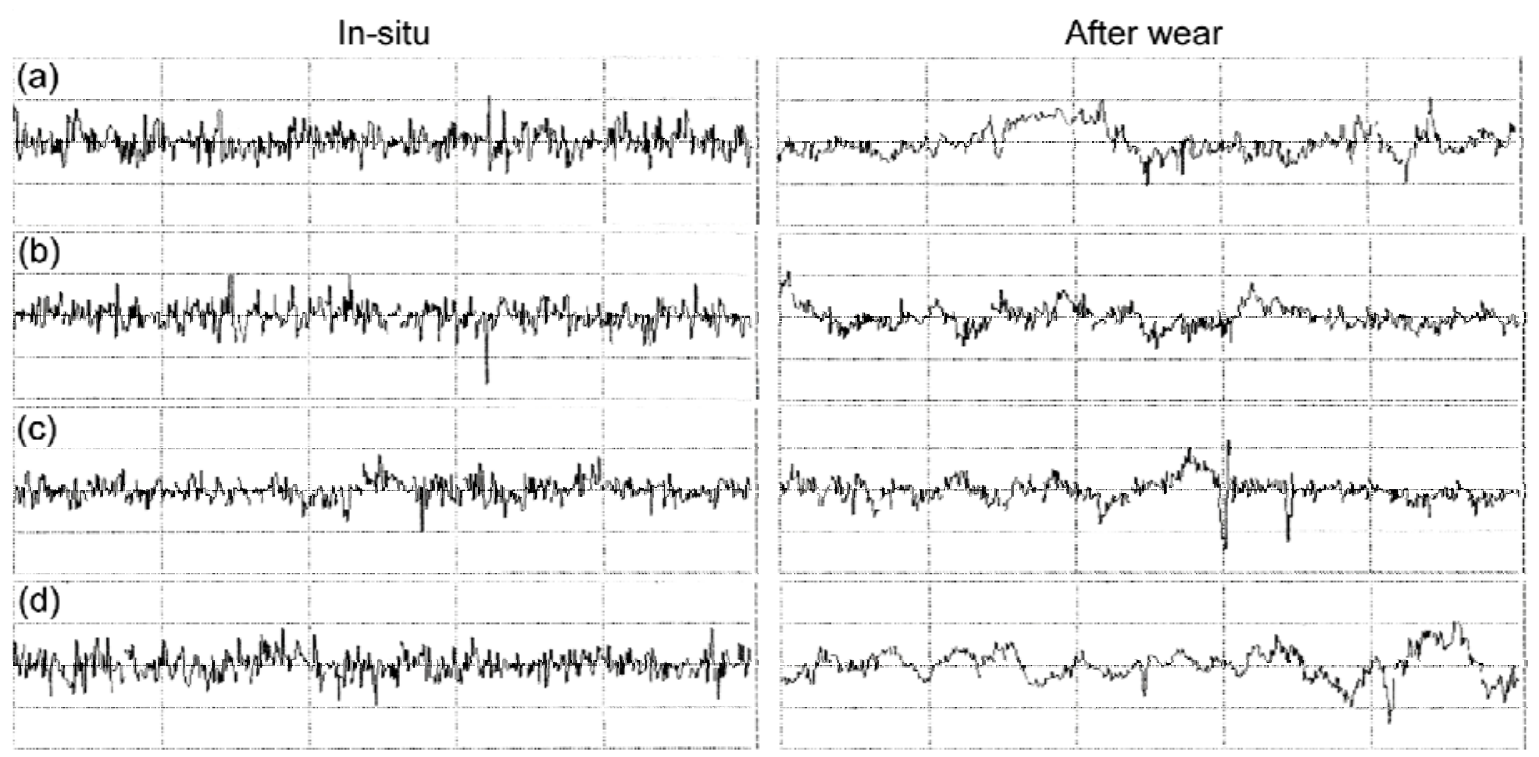

Fig.4. Profile records of the sample surfaces: (a) material CuSn10; (b) material CuSn10+FeAl; (c) material CuSn10+NiAl; (d) material CuSn10+TiCrAl (v.m. ×10000, h.m. ×50). 
It is easy to see that the presence of aluminides in the material leads to a slight decrease in roughness. Roughness parameters for all materials decreased after a wear cycle under stable load. This is due to the running-in ability of the tested materials under stable conditions. Under increased loading conditions roughness parameters of $\mathrm{CuSn} 10$ material increased after a wear cycle. It may be supposed that under increased load CuSn10 sintered bronze loses its fatigue strength and begins to break down. But for MMCs the tendency for a decrease in roughness was maintained. As far as roughness is concerned, CuSn10-NiAl MMC has the best results.

(a)
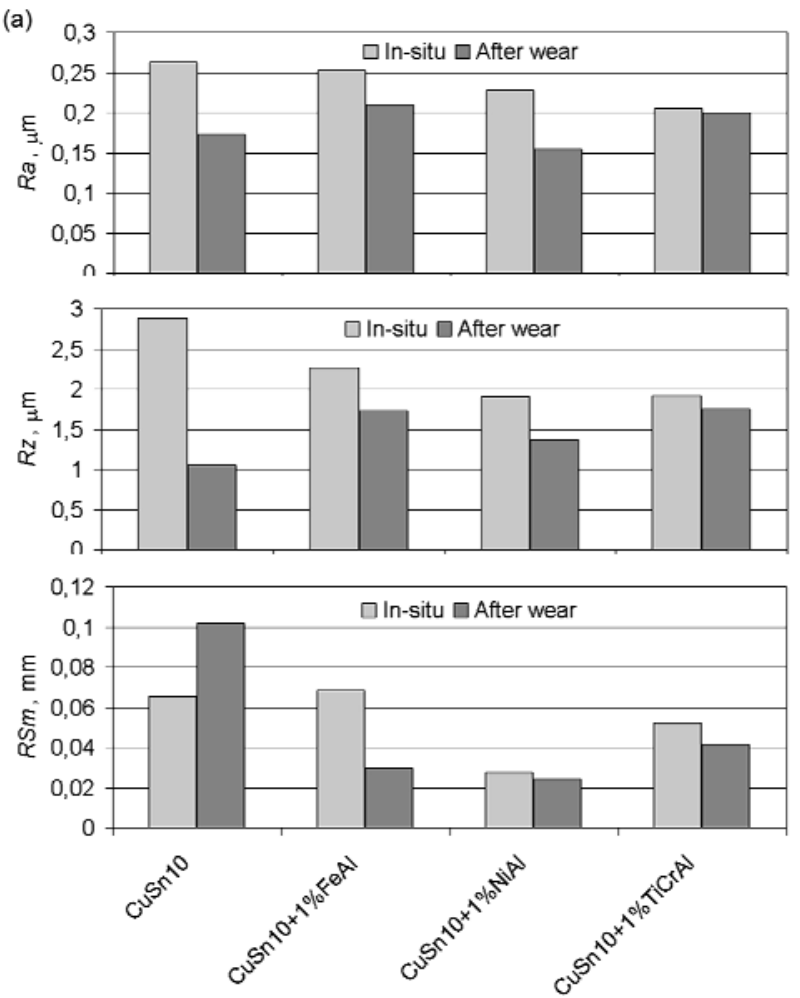

(b)
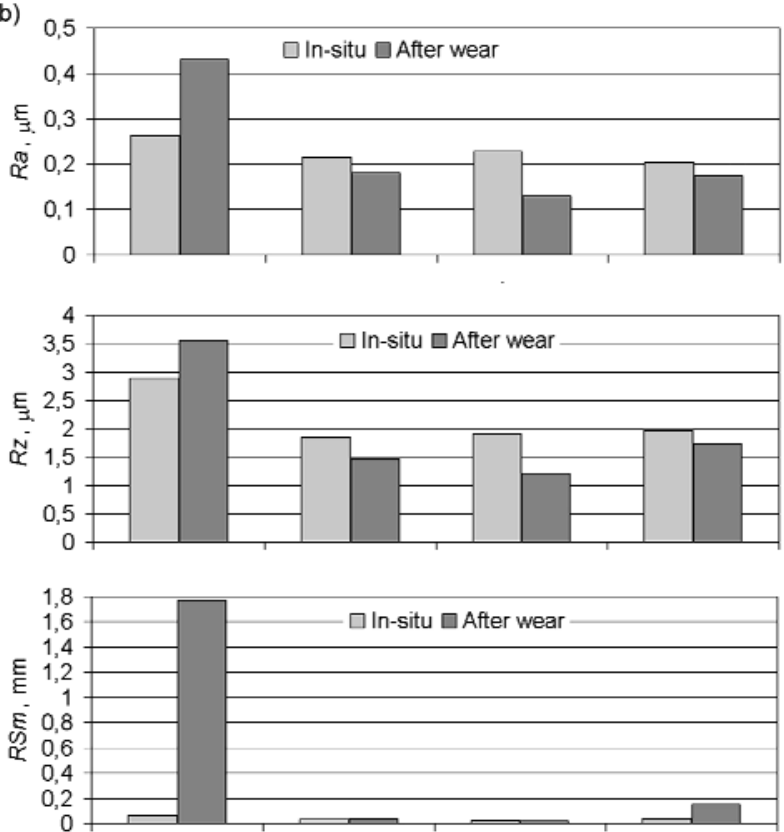

$5^{5^{50}}$
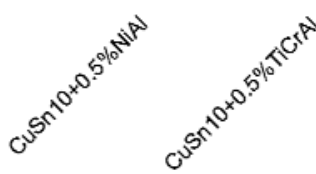

Fig.5. Surface roughness parameters of samples.

The wear rates of friction surfaces of the materials tested depend on their composition and loading conditions as shown in Fig.6. Wear rates increase significantly for increased loading conditions in comparison with stable loading. Increasing of the mass content of $\mathrm{NiAl}$ and $\mathrm{Ti}-\mathrm{Cr}-\mathrm{Al}$ aluminides hardly affects the MMCs wear rate, but in the case of FeAl aluminide the wear rate increases considerably. Increasing of the load value 2 times hardly affects the wear rates. Generally, the wear rate decreases in the direction of $\mathrm{FeAl} \rightarrow \mathrm{NiAl} \rightarrow \mathrm{Ti}-\mathrm{Cr}$-Al aluminides for all conditions and the advantage reaches about 20 times for the best MMC composition. 

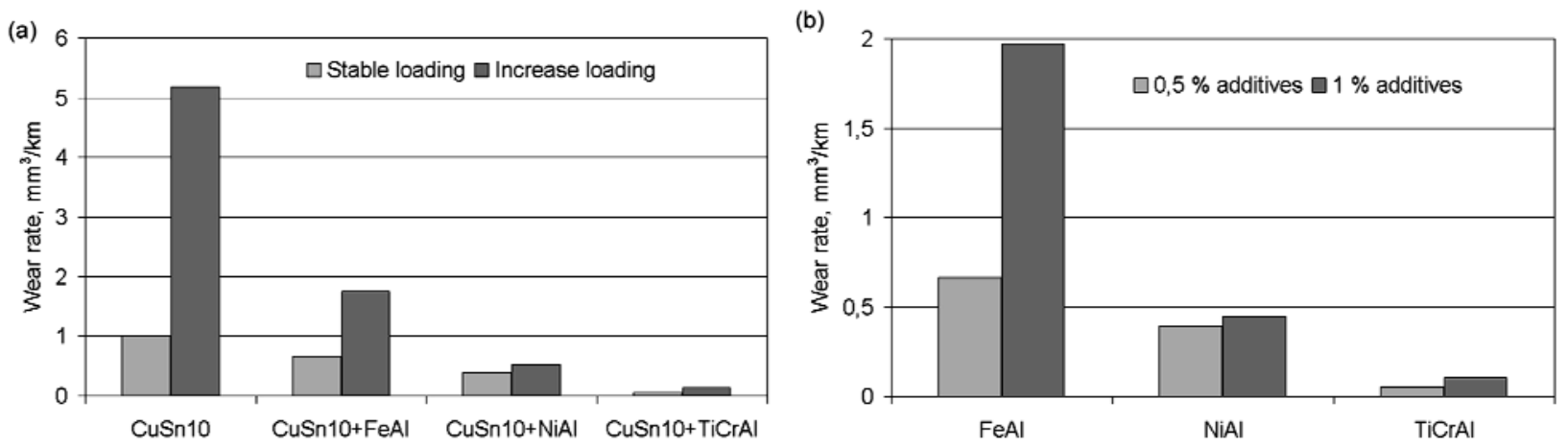

Fig.6. Wear rates of tested materials depending on friction conditions under concentrated loading: (a) under stable and increased loading for $0.5 \%$ reinforcing additives; (b) under stable loading for different mass content of additives.

Similar changes were also observed in MMCs under distributed loading (Fig.7). Tests performed under these conditions revealed that increasing the aluminides content decreases the wear rate. The wear resistance increases at the direction $\mathrm{NiAl} \rightarrow \mathrm{FeAl} \rightarrow \mathrm{TiCrAl}$ aluminides and reaches about 3.5 times for the best MMC composition. However, the mechanism of wear varies considerably.

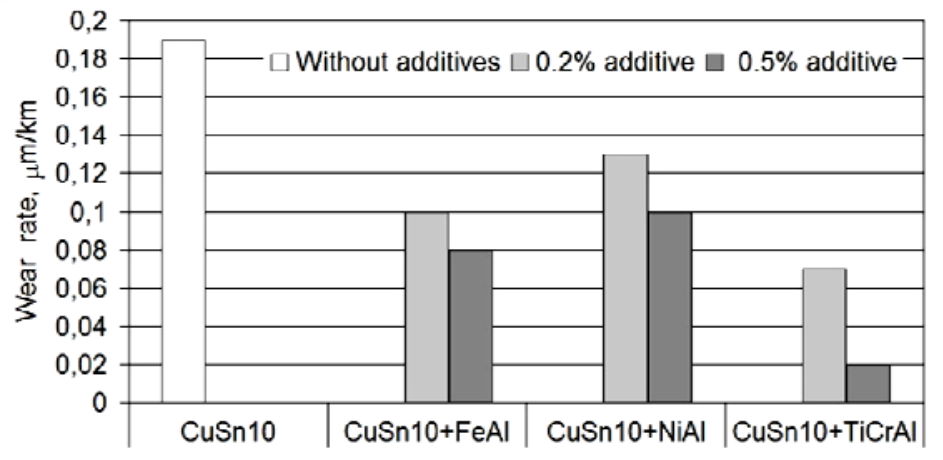

Fig.7. Wear rates of tested materials depending on the additive content under distributed loading.

Interconnected micro-craters along with traces of abrasive wear are observed on the friction surfaces (Fig.8). The intensity of micro-craters formation increases towards FeAl $\rightarrow \mathrm{NiAl} \rightarrow \mathrm{TiCrAl}$ aluminides. In our opinion, a specific contact, typical of materials containing hard microparticulates, is observed in this case. These microparticulates in the process of wear are concentrated at the "hardened steel - composite" interfaces, forming a kind of load-bearing elements. A similar effect was described by Díaz [10]; Hua et al. [21]; Dyachkova and Feldshtein [22]; Feldshtein et al. [23]. Due to this effect, as well as to the guaranteed presence of oil on the friction surfaces, the wear rate of composites is reduced significantly. This is indirectly confirmed by the previously described tests on the influence of the additives content and the load level on the wear rate.

\section{Conclusions}

1. The sintered bronze has the structure of the $\alpha$-solid solution of variable concentration, a small percentage of the $\alpha+\delta$ eutectoid inclusions, as well as a certain amount of pores. The bronze with aluminides additives has a finer structure. Inclusions of aluminides are observed mainly on the grain boundaries. Recrystallization was observed in the MMC during sintering. 
2. The presence of the aluminides in the MMC based on CuSn10 sintered bronze leads to increasing its hardness, but the flexural strength may increase or decrease depending on the chemical composition of aluminides. The best results were obtained for $\mathrm{NiAl} / 15 \% \mathrm{Al}_{2} \mathrm{O}_{3}$ reinforcing particulates.

3. The presence of aluminides in the material leads to a slight decrease in roughness. Roughness parameters for all materials decreased after a wear cycle under stable loading. Under increased loading conditions roughness parameters of CuSn10 material increased after a wear cycle but for MMCs the tendency for a decrease in roughness was maintained.

4. The presence of aluminides in the MMC reduces the wear rate considerably. It is decreased in the direction of $\mathrm{FeAl} / 15 \% \mathrm{Al}_{2} \mathrm{O}_{3} \rightarrow \mathrm{NiAl} / 15 \% \mathrm{Al}_{2} \mathrm{O}_{3} \rightarrow \mathrm{Ti}-8 \mathrm{Cr}-46 \mathrm{Al}$ aluminides and the advantage is about 20 times for the best MMC composition. In the MMCs wear process, micro-craters are formed on the contact surface and it is the principal reason of a decrease in the wear rate.
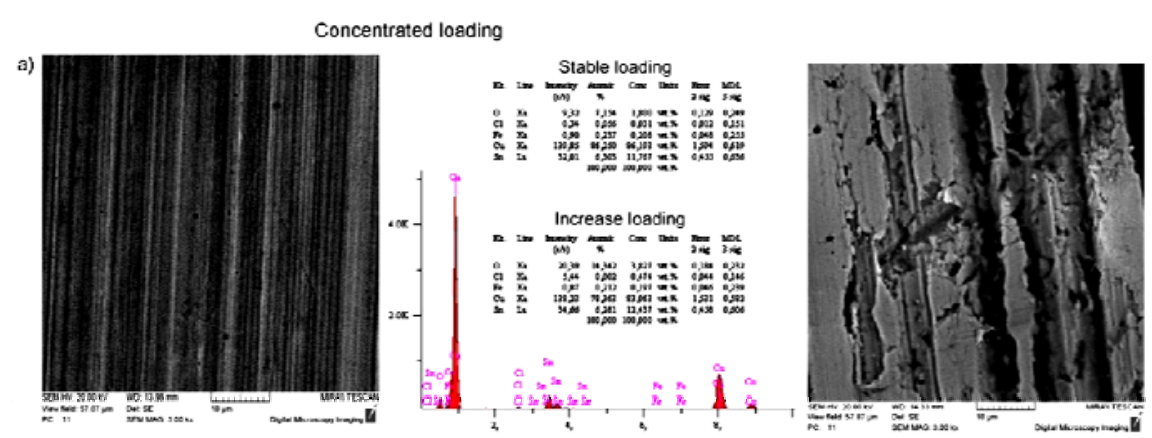

Distributed loading
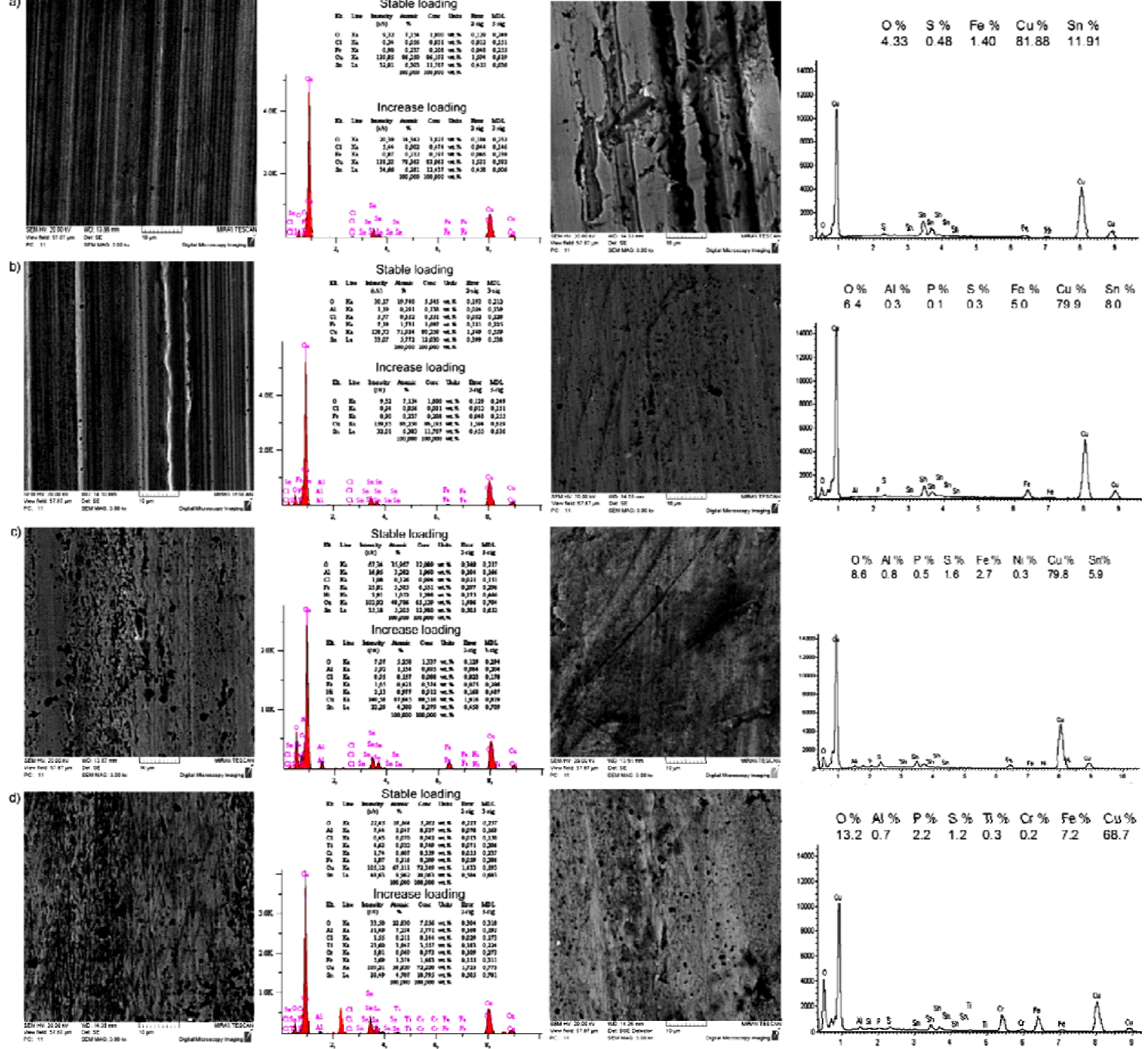

Fig.8. Results of SEM analysis of the samples after the wear cycle: (a) CuSn10; (b) CuSn10+FeAl; (c) CuSn10+NiAl; (d) CuSn10+TiCrAl. 


\section{References}

[1] Nadkarni A. (1998): Copper Powder Metallurgy Alloys and Composites. - In: Lee P.W., Trudel Y., Iacocca R., German R.M., Ferguson B.L., Eisen W.B., Moyer K., Madan D., Sanderow H., eds. Powder Metal Technologies and Applications. ASM Handbook, vol. 7. - ASM International, OH.

[2] Cusano C. (1994): Porous metal bearings. In: Monitoring, materials, synthetic lubricants and applications. - In: Booser E.R., ed. CRC Handbook of Lubricant and Tribology. vol. III. CRC Press, New York.

[3] Akhtar F., Askari S.J., Shah K.A., Du X. and Guo S. (2009): Microstructure, mechanical properties, electrical conductivity and wear behavior of high volume TiC reinforced Cu-matrix composites. - Mater. Charact., vol.60, No.4, pp.327-336.

[4] Deshpande P.K. and Lin R.Y. (2006): Wear resistance of WC particle reinforced copper matrix composites and the effect of porosity. - Mater. Sci. Eng. A., vol.418, No.1-2, pp.137-145.

[5] Tjong S.C. and Lau K.C. (2000): Tribological behaviour of SiC particle-reinforced copper matrix composites. Mater. Lett., vol.43, No.5-6, pp.274-280.

[6] Tjong S.C. and Lau K.C. (2000): Abrasive wear behavior of TiB ${ }_{2}$ particle-reinforced copper matrix composites. Mater. Sci. Eng. A., vol.282, No.1-2, pp.183-186.

[7] Tu J.P., Wang N.Y., Yang Y.Z., Qi W.X., Liu F., Zhang X.B., Lu H.M. and Liu M.S. (2002) Preparation and properties of $\mathrm{TiB}_{2}$ nanoparticle reinforced copper matrix composites by in situ processing. - Mater. Lett., vol.52, No.6, pp.448-452.

[8] Das D., Samanta A. and Chattopadhyay P.P. (2007): Synthesis of bulk nano- $\mathrm{Al}_{2} \mathrm{O}_{3}$ dispersed Cu-matrix composite using ball milled precursor. - Mater. Manuf. Process., vol.22, No.4, pp.516-524.

[9] Dyachkova L. and Feldshtein E.E. (2013): On the properties of composites based on sintered bronze with alumina additives. - Composites B., vol.45, No.1, pp.239-247.

[10] Díaz C., González-Carrasco J.L., Caruana G. and Liebich M. (1996): Ni ${ }_{3}$ Al intermetallic particles as wearresistant for al-base composites processed by powder reinforcement metallurgy. - Metal. Mater. Trans. A., vol.27, No.10, pp.3259-3266.

[11] Da Costa C.E., Zapata W.C., Velasco F., Ruiz-Prieto J.M. and Torralba J.M. (1999): Wear behaviour of aluminum reinforced with nickel aluminide MMCs. - J. Mater. Process. Technol., vol.92-93, pp.66-70.

[12] Tu J.P., Meng L. and Liu M.S. (1998): Friction and wear behavior of Cu-Fe ${ }_{3} \mathrm{Al}$ powder metallurgical composites in dry sliding. - Wear., vol.220, No.1, pp.72-79.

[13] Konieczny M. (2006): Laminar copper-intermetallics composite - generation and properties. - Composites. Theory and Practice, vol.6, No.4, pp.52-55.

[14] Konieczny M. and Mola R. (2007): Sintered copper matrix composites containing aluminium-ferric intermetallic phases. - Kompozyty, vol.7, No.2., pp.109-113 (in Polish).

[15] Çelikyürek İ., Körpe N.Ö., Ölçer T. and Galer R. (2011): Microstructure, properties and wear behaviors of $\left(\mathrm{Ni}_{3} \mathrm{Al}\right.$ ) p reinforced $\mathrm{Cu}$ matrix composites. - J. Mater. Sci. Technol., vol.27, No.10, pp.937-943.

[16] Zeren A., Feyzullahoglu E. and Zeren M. (2007) A study on tribological behaviour of tin-based bearing material in dry sliding. - Mater. and Des., vol.28, No.1, pp.318-323.

[17] Zeren A. (2007): Embeddability behaviour of tin-based bearing material in dry sliding. - Mater. and Des., vol.28, No.8, pp.2344-2350.

[18] Goudarzi M.M., Jahromi S.A.J. and Nazarboland A. (2009): Investigation of characteristics of tin-based white metals as a bearing material. - Mater. and Des., vol.30, No.6, pp.2283-2288.

[19] Gebretsadik D.W., Hardell J. and Prakash B. (2015): Tribological performance of tin-based overlay plated engine bearing materials. - Tribol. Int., vol.92, pp.281-289. 
[20] Sahin Y. (2003): Preparation and some properties of SiC particle reinforced aluminium alloy composites. - Mater. and Des., vol.24, No.8, pp.671-679.

[21] Hua K.H., Wang J., Schraube S., Xua Y.F., Hua X.G. and Stengler R. (2009): Tribological properties of MoS 2 nano-balls as filler in polyoxymethylene-based composite layer of three-layer self-lubrication bearing materials. Wear, vol.266, No.11-12, pp.1198-1207.

[22] Dyachkova L.N. and Feldshtein E.E. (2015): Morphology of worn surfaces of iron-graphite materials sintered or infiltrated with tin bronze. - Journal of Friction and Wear, vol.36, No.5, pp.395-399.

[23] Feldshtein E., Kowalewski P. and Dyachkova L. (2014): Studying the surface layers of products using a lowvacuum scanning electron microscope. - J. Surf. Invest. X-ray, Synchrotron and Neutron Techn., vol.8, No.6, pp.1258-1264.

Received: December 12, 2016

Revised: February 6, 2017 